\title{
USO DO PRODUTO MOD13Q1 DO SENSOR MODIS PARA ANÁLISE TEMPORAL E MAPEAMENTO DAS FLORESTAS NAS SERRAS DO SUDESTE E CAMPANHA MERIDIONAL DO RIO GRANDE DO SUL ${ }^{1}$
}

\author{
Ana Caroline Paim Benedetti ${ }^{2}$, Diogo Belmonte Lippert ${ }^{3}$, Rudiney Soares Pereira ${ }^{3}$, Cláudia Maria de
} Almeida $^{4}$, Claire Delfini Viana Cardoso ${ }^{2}$ e Elvis Rabuske Hendges ${ }^{5}$

\begin{abstract}
RESUMO - Imagens NDVI (Índice de Vegetação por Diferença Normalizada) do sensor Modis foram utilizadas para mapear as classes de uso e cobertura da terra nas Serras do Sudeste e Campanha Meridional do Rio Grande do Sul. A metodologia compreendeu a elaboração de um banco de dados espaciais e a aplicação de técnicas de processamento digital (contraste linear, classificação digital e operações aritméticas) sobre imagens dos satélites Landsat e Terra de diversas datas. Os resultados indicaram que a cobertura florestal passou de $8,6 \%$ para $11,6 \%$ e 14,3\% da área total da microrregião Serras do Sudeste, entre os anos 2000, 2004 e 2008. Na Campanha Meridional, a expansão da cobertura florestal passou de 11,1\% para 11,2\% e 11,5\% da área total no mesmo período. Conclui-se que imagens MOD13Q1, de baixa resolução espacial (250 m), podem ser usadas em grandes áreas para mapear florestas e os demais temas adequadamente.
\end{abstract}

Palavras-chave: Sensoriamento remoto; NDVI; Dinâmica florestal.

\section{PRODUCT MOD13Q1 MODIS SENSOR FOR TEMPORAL ANALYSIS OF FORESTS IN THE SERRAS DO SUDESTE AND CAMPANHA MERIDIONAL OF RIO GRANDE DO SUL}

\begin{abstract}
The NDVI(Vegetation Index Normalized Difference) Modis sensor was used to map the classes of land use and land cover of Serras do Sudeste and Campanha Meridional of Rio Grande do Sul. The methodology included the development of a spatial database and the application of digital signal processing techniques (linear contrast, digital classification and arithmetic operations) on Landsat satellite images and Terra of various dates. The results show that forest cover increased from $8.6 \%$ to $11.6 \%$ and $14.3 \%$ of the total area of Serras do Sudeste, between the years 2000, 2004 and 2008. In the Campanha Meridional, the expansion of forest cover increased from $11.1 \%$ to $11.2 \%$ and $11.5 \%$ of the total area in the same period. It is concluded that images MOD13Q1, low spatial resolution (250m), may be used to make maps of forest and other land use properly, in extensive areas.
\end{abstract}

Keywords: Remote sensing; NDVI; Forest dynamic.

\footnotetext{
${ }^{1}$ Recebido em 22.02.2012 aceito para publicação em 07.05.2013.

${ }^{2}$ Universidade Federal de Santa Maria, Colégio Politécnico, UFSM, Brasil. E-mail: <anacaroline@ politecnico.ufsm.br>e <cdvcardoso@gmail.com>.

${ }^{3}$ Universidade Federal de Santa Maria, Departamento de Engenharia Rural. E-mail: <diogo_b_lippert@ hotmail.com>e <rudiney@smail.ufsm.br>.

${ }^{4}$ Instituto Nacional de Pesquisas Espaciais, Coordenação Geral de Observação da Terra - Divisão de Sensoriamento Remoto. E-mail:<almeida@.dsr.inpe.br>.

${ }^{5}$ Universidade Estadual do Oeste do Paraná, Curso de Geografia. E-mail: <elvis_hendges@ @otmail.com>.
} 


\section{INTRODUÇÃO}

No ano de 2003, o governo do Rio Grande do Sul lançou o Programa Estadual de Florestamento que previa fomentar o plantio comercial em municípios da Metade Sul (SANTOS et al., 2007). Muito embora várias das predições com relação à consolidação de uma cadeia de base produtiva no setor florestal nessa região não tenham se confirmado, as ações efetivadas nos processos de implantação florestal já acarretam mudanças na paisagem regional. Nesse enfoque, uma das questões reside em elaborar metodologias capazes de monitorar processos de transição entre o bioma original (pampa) e a cobertura florestal.

Uma forma usual de se obterem mapas temporais para representar a paisagem constitui-se no emprego da técnica de classificação digital em imagens de satélite, processo no qual os temas da paisagem são categorizados em classes de acordo com critérios subjetivos da visão humana (VENTURIERE; SANTOS, 1998; MOREIRA, 2011; FLORENZANO, 2011; MIRANDA, 2011). Esse processo, no entanto, torna-se oneroso e mais suscetível ao erro quando nele são utilizados produtos orbitais de média e de baixa resolução espacial.

As imagens do sensor Moderate Resolution Imaging Spectroradiometer (Modis) a bordo do satélite Terra apresentam baixa resolução espacial e, em contrapartida, disponibilizam informações de alta periodicidade em uma escala global. É crescente o uso desse instrumento para mapear periodicamente atributos do meio ambiente, com notável destaque para o monitoramento da cobertura vegetal (RUDORFF et al., 2007; LIESENBERG et al., 2007; CARVALHO et al., 2008; COUTO JUNIOR et al., 2011).

O produto MOD13Q1, do sensor Modis, contém os índices de vegetação Normalized Difference Vegetation Index (NDVI) e Enhanced Vegetation Index (EVI) produzidos em escala global nas resoluções $1 \mathrm{~km}$, $500 \mathrm{~m}$ e $250 \mathrm{~m}$ em composições de imagens ou mosaicos de 16 dias. Esses índices permitem realizar estudos, tanto ao longo do tempo quanto no espaço, sobre as condições da cobertura vegetal, descrevendo e reconstituindo dados de variações fenológicas e discriminando variações interanuais da vegetação nas escalas global e regional (RUDORFF et al., 2007).

O NDVI é sensível à presença de clorofila e outros pigmentos da vegetação, responsáveis pela absorção da radiação solar na banda do vermelho (HUETE et al., 2002). Ele constitui o índice mais utilizado nos diversos estudos sobre a vegetação que envolve o uso dos dados de Sensoriamento Remoto (MOREIRA, 2011). É expresso pela razão entre a diferença da medida da reflectância $(\rho)$ nos canais do infravermelho próximo $(0,70-1,30 \mu \mathrm{m})$ e do vermelho $(0,55-0,70 \mu \mathrm{m})$ e a soma desses canais (ROUSE et al., 1974), ou seja: $N D V I=(\rho I V P-\rho V) /(\rho I V P+\rho V)$, em que $\rho I V P$ corresponde à resposta espectral do pixel na banda do infravermelho próximo, e $\rho V$ corresponde à resposta espectral do pixel na banda do vermelho visível. O valor do NDVI pode variar em uma escala entre -1 e 1 e, quanto mais próximo de 1 , maior a densidade de cobertura vegetal.

O objetivo deste trabalho foi utilizar o produto MOD13Q1 do sensor Modis para produzir mapas temporais que descrevam o comportamento espectral da vegetação e, com base nessas imagens, discriminar as tipologias "floresta", "regeneração", "campo" e "solo" nos anos 2000, 2004 e 2008 e avaliar suas transições durante esse período.

\section{MATERIAL E MÉTODOS}

\section{1. Áreas de estudo}

As microrregiões Serras do Sudeste e Campanha Meridional integram a Mesorregião Metade Sul, Rio Grande do Sul (Figura 1a). Fazem parte do Bioma Pampa, o qual ocupa uma área de aproximadamente $176.000 \mathrm{~km}^{2}$ no Estado, o equivalente a $64 \%$ do território gaúcho.

A vegetação é denominada estepe e savana estépica, que correspondem, respectivamente, aos campos do planalto e da campanha e à vegetação mais densa, arbustiva e arbórea nas encostas e ao longo dos cursos d'água, onde também aparecem as áreas de banhados. Conforme a classificação de W. Köppen, o clima predominante é do tipo Cfa, caracterizado como subtropical úmido, com chuvas regulares em todos os meses do ano. Os índices anuais de precipitação pluviométrica variam entre $1.300 \mathrm{~mm}$ e $1.500 \mathrm{~mm}$; as temperaturas médias anuais no Bioma Pampa estão entre $14^{\circ} \mathrm{C}$ e $18^{\circ} \mathrm{C}$ (MORENO, 1961). Nas Serras do Sudeste, destacam-se os afloramentos rochosos nas encostas e, nos altos platôs, a frequência de arbustos de diversas espécies resulta em paisagens que variam desde os "campos sujos" até as formações arbustivas compactas (RAMBO, 1942) e a hidrografia tem como curso principal o rio Camaquã. Já na Campanha Meridional 
as altitudes variam entre 90 e $450 \mathrm{~m}$ e constituem colinas suaves, campos planos e limpos e pequenas serras. A drenagem principal é formada pelos rios Santa Maria e Camaquã e a nascente do rio Negro, em Bagé, cujo curso corta o território uruguaio. As duas microrregiões são tipicamente agropecuárias, baseadas principalmente na criação extensiva do gado, influência da proximidade com os países platinos, em parte responsáveis pela diversidade das etnias formadoras da população.

\subsection{Elaboração do banco de dados e processamento digital de imagens}

Os dados foram processados no Sistema de Processamento de Informações Georreferenciadas SPRING, e para seu tratamento cartográfico foram adotados a projeção Policônica e o Datum WGS 84 (World Geodetic System 1984).

As imagens Landsat 5 TM (resolução espacial $30 \mathrm{~m}$ ) serviram como base para identificar as seguintes classes de uso e cobertura da terra: floresta (formações vegetais de porte arbóreo), regeneração (formação vegetal chamada popularmente de "capoeirão"), campo (vegetação rasteira, gramíneas) e solo (áreas de agricultura em pousio, solo exposto e lâmina de água).

Cinco cenas que recobrem as áreas de estudo foram selecionadas para o trabalho: órbita-ponto 222/081 de 27/09/2000, 04/07/2004 e 03/10/2008; 222/082 de 02/ 09/2000, 28/08/2004 e 10/10/2008; 223/081 de 20/05/ 2000, 06/10/2004 e 18/11/2008; 223/082 de 23/07/2000, 07/11/2004 e 18/11/2008; e 224/081 de 27/05/2000, 25/ 07/2004 e 08/10/2008. Essas imagens são disponibilizadas originalmente no formato GeoTiff, sendo convertidas e retificadas através da seleção de pontos de controle. Posteriormente, foram elaboradas as composições coloridas RGB 432 e 543 e aplicada a técnica de contraste linear (INPE, 2009), normalmente utilizada como préprocessamento para interpretação e classificação de imagens digitais.

Imagens do satélite TERRA, sensor Modis, produto MOD13Q1, quadrante h13v12, (resolução espacial 250 m), foram disponibilizadas pela National Aeronautics and Space Administration (NASA), sendo selecionadas as seguintes datas: 15/10/2000, 15/10/2004 e 15/11/2008.

Entre as cenas disponíveis, foram escolhidas as bandas espectrais Blue, Red, NIR, MIR e as imagens NDVI. Estas últimas imagens são disponibilizadas no formato original *.hdf (Hierarchical Data Format), e para a importação no aplicativo SPRING foi necessária a conversão para o formato *.GeoTiff através do aplicativo Modis Reprojection Tool MRT.

As imagens NDVI, convertidas para a resolução radiométrica de oito bits, foram transformadas para o formato numérico, através da exportação no formato ASC II e posterior importação para a geração de uma grade regular Modelo Numérico do Terreno(MNT) (Figura 1b), contemplando pixels com valores entre 0 e 255 níveis de cinza. As bandas Blue, MIR e NIR foram usadas para elaborar composições coloridas para discriminar padrões de vegetação, solo e água, equiparando-se visualmente às composições coloridas Landsat.

\subsection{Estratégia amostral para obtenção dos mapas de vegetação}

Para estabelecer uma correspondência entre as imagens Modis e as imagens Landsat, uma malha amostral de dimensão $3 \times 3$ pixels foi espacializada sobre as composições coloridas falsa-cor TM (Figura 1c). Cada amostra foi sobreposta às composições Modis (Figura 1c) e à grade MNT para leitura do ND (número digital) médio equivalente na imagem NDVI. A extração desse valor deu-se através da função "estatística da imagem por polígonos" do aplicativo SPRING. Os valores máximos e mínimos obtidos para cada classe de uso e cobertura estabeleceram os limiares para a operação de "fatiamento" das grades regulares (MDT) contendo os ND para toda a série temporal. Esses valores foram processados no aplicativo "R" (REIS; RIBEIRO JÚNIOR, 2007), sendo submetidos ao teste de comparação de médias de Tukey para verificar a heterogeneidade dos valores ND entre as classes de uma mesma data. Os mapas temáticos obtidos com o "fatiamento" das grades numéricas foram comparados com resultados da classificação digital e posteriormente submetidos ao simulador Dinamica Environment for Geoprocessing Objects (EGO) (SOARES-FILHO, 2009), para o cálculo de matrizes de transição entre as classes.

\subsection{Classificação digital de imagens Modis}

A classificação digital supervisionada foi executada sobre as imagens MOD13Q1 para posterior comparação com os resultados do "fatiamento". Utilizou-se o algoritmo classificador da máxima verossimilhança (MaxVer), que adota a função de densidade probabilística, baseada na estatística bayesiana, a qual verifica a probabilidade de cada pixel pertencer a determinada classe,

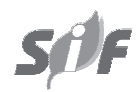

Revista Árvore, Viçosa-MG, v.37, n.3, p.459-467, 2013 


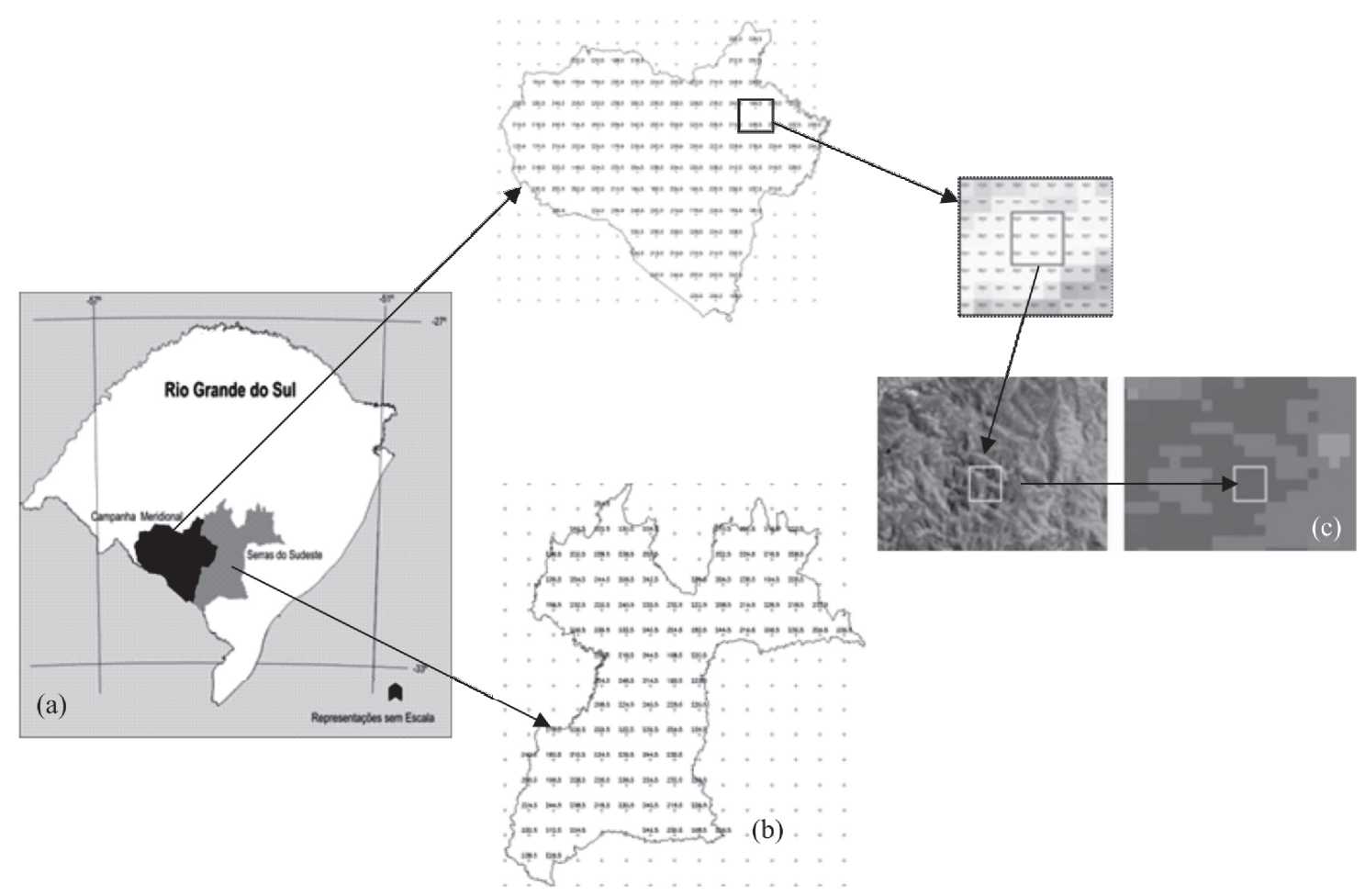

Figura1 - Localização das áreas de estudo no Estado do Rio Grande do Sul, Brasil (a); grade numérica do NDVI nas microrregiões Campanha Meridional e Serras do Sudeste (b); e unidade amostral poligonal sobre as imagens Landsat e Modis (c).

Figure 1 - Location of study areas in the Rio Grande do Sul, Brazil (a); grid of NDVI in the Campanha Meridional and Serras do Sudeste (b); and samples on Landsat and Modis images(c).

englobando-a na de maior probabilidade (VENTURIERE; SANTOS, 1998). A qualidade das amostras da classificação digital foi avaliada através do índice Kappa (LANDIS; KOCH, 1977).

\section{RESULTADOS}

\subsection{Análise estatística das amostras e elaboração dos mapas temáticos da vegetação}

Para elaborar os mapas de vegetação foi executado o "fatiamento" das imagens MOD13Q1, considerando-se como limiares o ND máximo e o mínimo para cada classe (Tabela 1).

A definição dos limiares entre os ND para caracterizar cada classe requer a comprovação da heterogeneidade entre as amostras e, para tal, foi aplicada uma análise de variância - ANOVA. Para as Serras do Sudeste, a ANOVA indicou que as amostras diferem-se significativamente em nível $\alpha \leq 5 \%$ de probabilidade de erro $(\operatorname{Pr}<2,2 e-16)$, obtendo-se F calculado igual a 2.977,9; 3.278,3; e 3.940,3, respectivamente. As amostras tomadas na Campanha Meridional diferem-se significativamente em nível $\alpha \leq 5 \%$ e probabilidade de erro $(\operatorname{Pr}<2,2 e-16)$, pois se obteve F calculado igual a $3.290,5 ; 3.338,9$; e 4.891,8 para os anos 2000, 2004 e 2008 .

O teste de Tukey foi aplicado posteriormente e comprovou que entre todas as classes ocorrem diferenças significativas em nível $\alpha \leq 5 \%$. Assim, para as duas microrregiões, as observações são distintas em relação ao comportamento espectral de cada classe, sendo, portanto, passível seu uso como indicadoras do comportamento da respectiva classe em toda a imagem.

\subsection{Classificação digital e sua comparação com os mapas de vegetação}

Os resultados possibilitaram a quantificação das classes e sua comparação com as áreas determinadas

Revista Árvore, Viçosa-MG, v.37, n.3, p.459-467, 2013 
Tabela 1 - Estatística do conjunto amostral dos ND e limiares (máximo e mínimo) para o fatiamento da imagem MOD13Q1 nas microrregiões Serras do Sudeste (SS) e Campanha Meridional (CM).

Table 1 - Statistics of ND and maximum and minimum thresholds for image slicing MOD13Q1 in the regions of Serras do Sudeste (SS) and Campanha Meridional (CM).

\begin{tabular}{|c|c|c|c|c|c|c|c|c|}
\hline \multirow{3}{*}{ Parâmetros } & \multicolumn{8}{|c|}{ Imagens MOD13Q1 de 15/10/2000 } \\
\hline & \multicolumn{2}{|c|}{ Floresta } & \multicolumn{2}{|c|}{ Regeneração } & \multicolumn{2}{|c|}{ Campo } & \multicolumn{2}{|c|}{ Solo } \\
\hline & SS & $\mathrm{CM}$ & SS & $\mathrm{CM}$ & SS & $\mathrm{CM}$ & SS & $\mathrm{CM}$ \\
\hline Média & 250,0 & 247,4 & 242,8 & 237,3 & 223,1 & 225,7 & 175,6 & 176,0 \\
\hline Variância & 11,7 & 17,7 & 1,2 & 2,4 & 13,6 & 8,8 & 103,3 & 88,2 \\
\hline Desvio-padrão & 3,4 & 4,2 & 1,1 & 1,5 & 3,7 & 3,0 & 10,1 & 9,4 \\
\hline $\mathrm{CV} \%$ & 1,4 & 1,7 & 0,4 & 0,6 & 1,6 & 1,3 & 5,7 & 5,3 \\
\hline Limiar de fatiamento (ND) & 255245 & 255240 & 244241 & 239235 & 229216 & 231221 & 190160 & 189163 \\
\hline Parâmetros & \multicolumn{8}{|c|}{ Imagens MOD13Q1 de 15/10/2004 } \\
\hline Média & 250,8 & 248,1 & 243,0 & 238,3 & 222,9 & 222,4 & 177,4 & 173,0 \\
\hline Variância & 8,2 & 15,7 & 1,5 & 4,0 & 12,5 & 16,4 & 109,2 & 97,0 \\
\hline Desvio-padrão & 2,8 & 3,9 & 1,2 & 2,0 & 3,5 & 4,0 & 10,5 & 9,8 \\
\hline C. V.\% & 1,1 & 1,6 & 0,5 & 0,8 & 1,6 & 1,8 & 5,9 & 5,7 \\
\hline Limiar de fatiamento(ND) & 255246 & 255241 & 245241 & 241235 & 229217 & 229216 & 191160 & 187160 \\
\hline Parâmetros & \multicolumn{8}{|c|}{ Imagens MOD13Q1 de 15/10/2008 } \\
\hline Média & 250,3 & 250,5 & 242,2 & 242,8 & 222,0 & 223,3 & 174,2 & 171,7 \\
\hline Variância & 9,0 & 6,2 & 1,8 & 2,5 & 15,4 & 15,9 & 86,8 & 73,9 \\
\hline Desvio-padrão & 3,0 & 2,4 & 1,4 & 1,6 & 3,9 & 3,9 & 9,3 & 8,6 \\
\hline C. V.\% & 1,2 & 0,9 & 0,6 & 0,7 & 1,7 & 1,7 & 5,3 & 5,0 \\
\hline Limiar de fatiamento(ND) & 255245 & 255245 & 244240 & 244240 & 229216 & 230216 & 188159 & 185159 \\
\hline
\end{tabular}

de acordo com o processo de fatiamento (Tabela 2), para elaboração dos mapas de vegetação (Figura 2).

\subsection{Transições entre as classes de vegetação}

As transições na vegetação foram analisadas através de matrizes geradas no aplicativo Dinamica EGO, considerando-se os dois intervalos de simulação, 2000 a 2004 e 2004 a 2008. Nelas são indicadas as taxas percentuais de transição ao longo do intervalo de simulação e, com base nesses resultados, foi calculado o valor em área (ha), referente aos processos de conversão (redução e expansão) entre as classes durante os dois períodos (Tabela 3).

\section{DISCUSSÃO}

A Tabela 1 mostra que os limiares definidos para as classes são distintos e podem ser usados para caracterizar as diferentes tipologias da vegetação. Embora os valores tenham sido obtidos por meio de amostragem, observou-se que o comportamento de uma mesma classe era semelhante em todas as datas, e o fatiamento das grades deu-se praticamente pelos mesmos limiares ao longo do tempo. Essa observação é válida para as duas microrregiões de estudo.
Quanto à classificação digital, a confiabilidade das amostras de acordo com o índice Kappa, determinado para as Serras do Sudeste nos anos 2000, 2004 e 2008, corresponde a 0,$967 ; 0,974$; e 0,958 , respectivamente. Para a Campanha Meridional, os coeficientes Kappa foram de 0,994; 0,954; e 0,987, nas mesmas datas. Os resultados são considerados excelentes, segundo a qualificação apresentada por Landis e Koch (1977).

As áreas de campo onde ocorre o pastoreio extensivo do gado são predominantes na paisagem das microrregiões. A ocorrência das áreas de solo exposto e água é distinta nas duas microrregiões. Nas Serras do Sudeste, as áreas de solo compreendem agricultura em pousio nessa época do ano, mas muitas vezes constituem áreas impróprias ao uso agrícola devido à ocorrência de solos pobres e de afloramentos rochosos. Já na microrregião Campanha Meridional quase que a totalidade das áreas de solo e água compreende agricultura irrigada também em pousio nesse período.

A quantificação das áreas, calculada através do "fatiamento", apresenta valores muito próximos àqueles calculados por meio da classificação digital, se considerada a baixa resolução espacial do pixel, que 
Tabela 2 - Áreas das classes temáticas por meio da classificação digital e do fatiamento da imagem MOD13Q1. Table 2 - Areas of classes through digital classification and slicing the image of MOD13Q1.

\begin{tabular}{|c|c|c|c|c|c|c|c|c|c|}
\hline \multicolumn{10}{|c|}{ Serras do Sudeste } \\
\hline Classe & Classif. & Fatiam. & Dif. $\left(\mathrm{km}^{2}\right)$ & Classif. & Fatiam. & Dif. $\left(\mathrm{Km}^{2}\right)$ & Classif. & Fatiam. & Dif. \\
\hline \multicolumn{4}{|c|}{$15 / 10 / 2000\left(\mathrm{~km}^{2}\right)$} & \multicolumn{3}{|c|}{ 15/10/2004 $\left(\mathrm{km}^{2}\right)$} & \multicolumn{3}{|c|}{$15 / 10 / 2008\left(\mathrm{~km}^{2}\right)$} \\
\hline Solo & 2771,0 & $2.766,5$ & $-4,5$ & 2561,3 & $2.567,8$ & 6,7 & 2490,3 & $2.496,3$ & 6 \\
\hline Campo & $11.810,3$ & $11.801,1$ & $-9,2$ & $10.832,1$ & $10.837,1$ & 5 & $9.920,3$ & $9.911,9$ & $-8,2$ \\
\hline Regeneração & 524,7 & 531,9 & 7,2 & $1.209,1$ & $1.206,2$ & $-3,2$ & $1.751,4$ & $1.745,9$ & $-5,5$ \\
\hline Floresta & $1.416,8$ & $1.423,3$ & 6,5 & $1.920,3$ & $1.911,7$ & $-8,5$ & $2.360,8$ & $2.368,7$ & 7,9 \\
\hline Total & \multicolumn{2}{|c|}{$16.522,8$} & \multicolumn{4}{|c|}{$16.522,8$} & \multicolumn{3}{|c|}{$16.522,8$} \\
\hline \multicolumn{10}{|c|}{ Campanha Meridional } \\
\hline Solo & $5.501,1$ & $5.508,7$ & 7,7 & 3766,7 & $3.771,5$ & 4,7 & 3497,9 & $3.492,4$ & $-5,5$ \\
\hline Campo & $5.869,0$ & $5.860,7$ & $-8,2$ & $7.255,4$ & $7.249,1$ & $-6,2$ & $7.075,2$ & $7.082,5$ & 7,2 \\
\hline Regeneração & $1.312,9$ & $1.306,2$ & $-6,5$ & $1.648,0$ & $1.641,5$ & $-6,5$ & $2.034,8$ & $2.039,6$ & 4,7 \\
\hline Floresta & $1.578,1$ & $1.585,5$ & 7,4 & $1.591,0$ & 1.599 & 8 & $1.653,2$ & $1.646,6$ & $-6,5$ \\
\hline Total & \multicolumn{2}{|c|}{$14.261,1$} & \multicolumn{4}{|c|}{$14.261,1$} & \multicolumn{3}{|c|}{$14.261,1$} \\
\hline
\end{tabular}
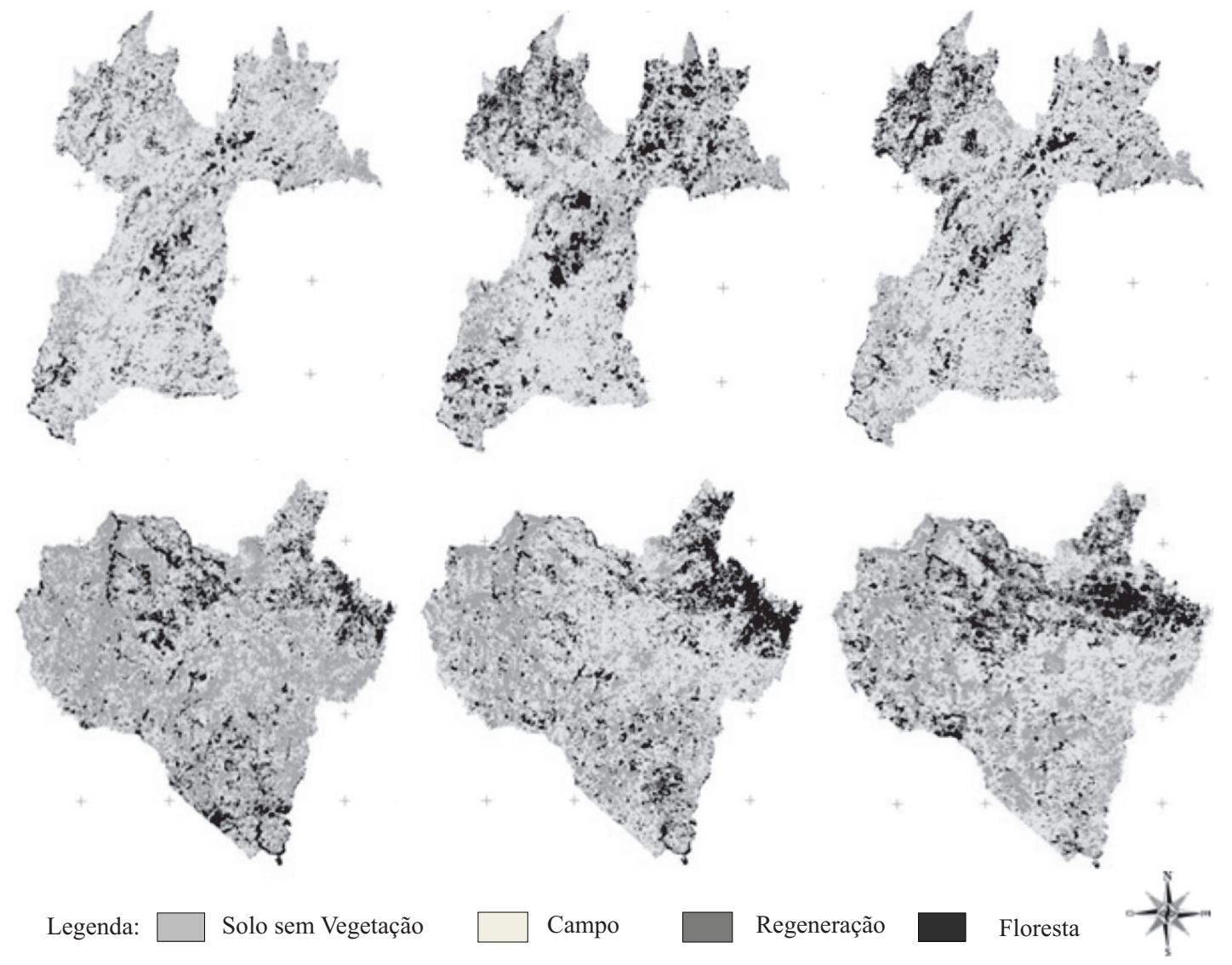

Figura 2 - Mapas de vegetação nas microrregiões Serras do Sudeste e Campanha Meridional, em 15/10/2000, 15/10/2004 e $15 / 10 / 2008$.

Figure 2 - Vegetation maps in the microregion Serras do Sudeste and Campanha Meridional in 10/15/2000, 10/15/2004 and 10/15/2008.

Revista Árvore, Viçosa-MG, v.37, n.3, p.459-467, 2013 
Tabela 3 - Conversão entre as classes nas microrregiões Serras do Sudeste e Campanha Meridional, nos dois períodos de análise, em valores de área (ha).

Table 3 - Conversion between the classes in the Serras do Sudeste and Campanha Meridional in the two study periods, in values of area $(h a)$.

\begin{tabular}{|c|c|c|c|c|}
\hline \multicolumn{5}{|c|}{ Serras do Sudeste entre 2000 e 2004} \\
\hline De\Para & Solo & Campo & Regeneração & Floresta \\
\hline Solo & $\mathrm{xx}$ & $131.418,8$ & $3.418,75$ & $7.025,0$ \\
\hline Campo & $116.562,5$ & $\mathrm{xx}$ & $88.843,75$ & $82.550,0$ \\
\hline Regeneração & $1.387,5$ & $25.575,0$ & $\mathrm{xx}$ & $16.568,75$ \\
\hline Floresta & $4.050,0$ & $3.556,25$ & $18.700,0$ & $\mathrm{xx}$ \\
\hline \multicolumn{5}{|c|}{ Serras do Sudeste entre 2004 e 2008} \\
\hline De\Para & Solo & Campo & Regeneração & Floresta \\
\hline Solo & $\mathrm{xx}$ & $107.600,0$ & $9.756,25$ & $21.918,75$ \\
\hline Campo & $122.331,25$ & $\mathrm{xx}$ & $92.281,25$ & $103.193,75$ \\
\hline Regeneração & $3.881,25$ & $65.087,5$ & $\mathrm{xx}$ & $23.331,25$ \\
\hline Floresta & $5.912,5$ & $52.606,25$ & $44.231,25$ & $\mathrm{xx}$ \\
\hline \multicolumn{5}{|c|}{ Campanha Meridional entre 2000 e 2004} \\
\hline De $\backslash$ Para & Solo & Campo & Regeneração & Floresta \\
\hline Solo & $\mathrm{xx}$ & $247.081,25$ & $19.068,75$ & $14.787,5$ \\
\hline Campo & $89.062,5$ & $\mathrm{xx}$ & $80.237,5$ & $43.387,5$ \\
\hline Regeneração & $8.675,0$ & $59.887,5$ & $\mathrm{xx}$ & $30.831,25$ \\
\hline Floresta & $9.475,0$ & $44.550,0$ & $33.618,75$ & $\mathrm{xx}$ \\
\hline \multicolumn{5}{|c|}{ Campanha Meridional entre 2004 e 2008} \\
\hline De $\backslash$ Para & Solo & Campo & Regeneração & Floresta \\
\hline Solo & $\mathrm{xx}$ & $140.306,3$ & $17.543,75$ & $11.587,5$ \\
\hline Campo & $119.518,8$ & $\mathrm{xx}$ & $105.393,8$ & $62.625,0$ \\
\hline Regeneração & $12.437,5$ & $78.243,75$ & $\mathrm{xx}$ & $36.262,5$ \\
\hline Floresta & $9.568,75$ & $52.331,25$ & $43.818,75$ & $\mathrm{xx}$ \\
\hline
\end{tabular}

representa 6,25 ha de área no terreno. Os resultados demonstram expansão na cobertura florestal, bem como nas áreas de regeneração nas duas microrregiões, sobretudo nas Serras do Sudeste. Devido à maior influência das atividades agropecuárias na Campanha Meridional, esse acréscimo é menos expressivo.

Nos mapas de vegetação (Figura 2), observa-se que no ano 2000 as duas microrregiões têm suas principais áreas florestais nos cursos d'água, caracterizando a presença de mata ciliar, e ainda em áreas de maiores declives, como nas porções Noroeste das Serras do Sudeste e nas porções Nordeste da Campanha Meridional. Ao longo do período foi notável a expansão das áreas de floresta; observa-se, nos anos 2004 e principalmente 2008, oincremento de plantios florestais na porção central das Serras do Sudeste e a expressiva evolução da floresta e da regeneração na porção Norte dessa mesmamicrorregião. Denota-se maior concentraçãodeflorestas e de regeneração na parte Norte da Campanha Meridional; é também nessas imediações que se concentra a maior parte das florestas plantadas. As áreas de solo e campo, no entanto, foram reduzidas ao longo do período, indicando a ocorrência de processos de conversão de uso da terra entre tais classes.

Segundo a matriz de transição entre as classes, na microrregião Serras do Sudeste, entre 2000 e 2004, a redução de áreas florestais, dada pela conversão dessa classe para outras classes, totalizou 57.306,25 ha, no entanto sua expansão compreendeu 106.143,75 ha. Na mesma microrregião, entre 2004 e 2008, a redução florestal foi quantificada em 102.750 ha, e a expansão novamente obteve área superior, sendo quantificada em 148.443,8 ha. Na microrregião Campanha Meridional foi quantificada, no primeiro período, uma redução de áreas florestais de 87.643,75 ha, sendo o acréscimo calculado em $89.006,25$ ha. No segundo período, entre 2004 e 2008, a redução da cobertura florestal totalizou 105.718,8 ha, sendo o seu acréscimo contabilizado em 110.475 ha. Os valores de expansão florestal, quando agregados às áreas de manutenção florestal, representam a totalidade dessa classe em cada data de análise, comprovando a evolução da cobertura

Revista Árvore, Viçosa-MG, v.37, n.3, p.459-467, 2013 
florestal nas duas microrregiões. Entre os processos observados, destacam-se as conversões da classe "campo" para "regeneração" e para "floresta", denotando ser essa classe a maior responsável pela expansão quantificada.

Os mapas de vegetação indicam que a cobertura florestal passou de $8,6 \%$ para $11,6 \%$ e $14,3 \%$ da área total da microrregião Serras do Sudeste, respectivamente nos anos 2000, 2004 e 2008. Na Campanha Meridional, a expansão da cobertura florestal passou de $11,1 \%$ para $11,2 \%$ e 11,5\% da área total nos anos 2000, 2004 e 2008. Embora a representação das florestas nos mapas tenha sido generalizada, a expansão florestal é dada de duas formas distintas. A primeira atribui-se ao estabelecimento da regeneração e posterior formação florestal nativa observada, na maioria das vezes, ao longo da rede de drenagem, em áreas de maior declividade e, muitas vezes, em áreas anteriormente utilizadas para a atividade agropecuária. Os produtores, algumas vezes por falta de investimentos, deixam de explorar áreas agrícolas, permitindo que a vegetação se regenere. Embora essa expansão represente, em parte, o cumprimento da legislação vigente quanto às Áreas de Preservação Permanente (APP), ela está, por vezes, associada negativamente ao abandono de áreas agricultáveis, à diminuição de renda da população local e ao êxodo rural. A legislação para proteção ambiental e as práticas de fiscalização tornaram-se, com o passar dos anos, mais rigorosas; a aplicação das multas e mesmo a conscientização da população contribuem para a manutenção e acréscimo dos recursos florestais. A segunda forma de expansão florestal está atrelada à introdução de espécies exóticas, principalmente de Eucalyptus, Pinus e Acacia, por meio de florestamentos e reflorestamentos. Tal conversão de uso da terra nas microrregiões visa suprir a demanda de matéria-prima por parte de empresas privadas, sobretudo as do setor de celulose e papel, fortalecendo o segmento industrial e movimentando a economia local. Em muitas propriedades rurais, a prática da silvicultura vem sendo empregada em consórcio com culturas agrícolas e com a pecuária (sistemas agrossilvipastoris), acenando como fonte alternativa de renda para os produtores.

\section{CONCLUSÃO}

O monitoramento das imagens MOD13Q1 na série temporal permitiu distinguir os limiares para floresta, regeneração, campo e solo e comparar esses mapas com aqueles obtidos por classificação digital. Podese inferir que valores de referência para a imagem MOD13Q1 podem ser usados para distinguir classes de uso e cobertura da terra em imagens de baixa resolução espacial $(250 \mathrm{~m})$. No entanto, é necessária a adoção de valores distintos e independentes com relação à base temporal. Limitações ao uso desse produto residem na impossibilidade de se distinguirem corretamente áreas de florestamento de espécies exóticas de áreas de floresta nativa. Em conformidade com a escala e a resolução espacial adotadas nesta pesquisa, tais temas foram generalizados, pressupondo-se que, por vezes, as áreas de silvicultura foram dispostas na classe floresta e outras vezes, em função de seu estágio vegetativo, foram dispostas na classe regeneração.

\section{REFERÊNCIAS}

CARVALHO, F. M. V. et al.Padrões de autocorrelação espacial de índices de vegetação Modis no bioma cerrado. RevistaÁrvore, v.32, n.2. p.279-290, 2008.

COUTO JUNIOR, A. F. et al.Tratamento de ruídos e caracterização de fisionomias do cerrado utilizando séries temporais do sensor Modis. Revista Árvore, v.35, n.3. p.699-705, 2011.

FLORENZANO, T. G. Iniciação ao

Sensoriamento Remoto. 3.ed. São Paulo: Oficina de Textos, 2011. 128p.

HUETE, A. et al. Overview of the radiometric and biophysical performance of the MODIS vegetation indices. Remote Sensing of

Environment, v.83, n.1/2, p.195-213, 2002.

INSTITUTO BRASILEIRO DE GEOGRAFIA E ESTATÍSTICA-IBGE.Disponível em:http:// www.ibge.gov.br. Acesso em: 26 jun. de 2009.

\section{INSTITUTO NACIONAL DE PESQUISAS}

ESPACIAIS- INPE. São José dos Campos: 2009. Disponível em: http://www.inpe.br. Acessoem: 10 maio 2009.

LANDIS, J. R.; KOCH, G. G. The measurement of observer agreement for categorical data. Biometrics, v.33, n.1, p.159-174, 1977. 
LIESENBERG, V.; PONZONI, F. J.; GALVÃO, L. S. Análise da dinâmica sazonal e separabilidade espectral de algumas fitofisionomias do cerrado com índices de vegetação dos sensores Modis/ Terra e Aqua. Revista Árvore,v.31, n.2. p.295-305, 2007.

Miranda, J. I. Processamento de imagens digitais: métodos multivariados em Java. Campinas: Embrapa Informática Agropecuária, 2011.319p.

MOREIRA, M. A. Fundamentos do sensoriamento remoto e metodologias de aplicação. 4.ed. Viçosa, MG: Universidade Federal deViçosa, 2011. 422p.

Moreno, J. A. Clima do Rio Grande do Sul. Porto Alegre: Secretaria da Agricultura, 1961. 42p.

RAMBO, B. A fisionomia do Rio Grande do Sul: ensaio de monografia natural. Porto Alegre: Imprensa Oficial, 1942. 456p.

REIS, G. M.; RIBEIRO JÚNIOR, J. I. Ferramentas estatísticas básicas da qualidade - guia prático do R. 2007. Disponível em: http://

www.estatísticanor.xpg.com.br. Acesso em: 15 jan. 2010.
ROUSE, J. W. et al. Monitoring the Vernal Advancement and retrogradation

(Green Wave Effect) of natural vegetation. Greenbelt:NASA/GSFC, 1974. 371p. (Type III Final Report)

RUDORFF, B. F. T.; SHIMABUKURO, Y. E.; CEBALlos, J. C. O Sensor MODIS e suas aplicações ambientais no Brasil. São José dos Campos: Parêntese, 2007. 423 p.

SANTOS, O. I. B. et al. Perspectivas de desenvolvimento sustentável da metade Sul do Rio Grande do Sul com base nos arranjos silvícolas emergentes e na produção de etanol a partir de celulose. In: ENCONTRO NACIONAL SOBRE GESTÃO EMPRESARIAL E MEIO

AMBIEnTE, 9., 2007, Curitiba. Anais... Curitiba: ENGEMA, 2007. p.1-17.

SOARES-FILHO, B. S.; RODRIGUES, H.; LELLES, W. Modelingenvironmental dynamics withdinamica EGO. Belo Horizonte: CSR, 2009. v.1. 115p.

VENTURIERE, A.; SANTOS, J. R. Técnicas de classificação de imagens para análise da cobertura vegetal.In: ASSAD, E. D.; SANO, E. E. (Org.). Sistemas de informações geográficas: aplicações na agricultura. 2.ed. Brasília: Embrapa, 1998. p.351-371. 
